Kohl: a Journal for Body and Gender Research

Vol. 3, No. 1 (Summer 2017)

\title{
The Human Trap
}

Hala H. Hassan 
Hala H. Hassan is a Lebanese designer and illustrator currently residing in New York City. She is interested in design activism and how we can develop human-centered designs/innovations with social impact.

When Hala decided to extend her stay in New York in the beginning of 2017, she launched a personal project "Randomiyyat," that goes by the "rule of three." She posts series of three images she took or three illustrations she drew that talk about socio-political or personal experiences especially in the new environment she is living in. That was timed with all the major changes that were happening in the world and that country in specific.

The series featured here is titled "The Human Trap" and was first published on the online publication of the New York-based art organization "The Seventh Wave" on February 19, 2017, which happens to be Presidents' Day in the United States, to serve an implied message of opposition.

This series sheds the light on the subjects themselves in the migration equation. Migration is mostly addressed from the different socio political and economic impacts but we fail to acknowledge the subject and their challenges and experiences that is also defined as alienation.

When an access card to bigger ambitions and dreams becomes a trap, a nightmare. When a person is feared and framed as an alien and when words jeopardize the existence of its voice. That is the new reality we have created for the people who seek to change their dark destinies or choose to walk away from their comfort zone or are just forced to find a new home. That is the life of an alien.

Note: the characters are all gender neutral and the continuation of this series is featured in this issue of Kohl. 


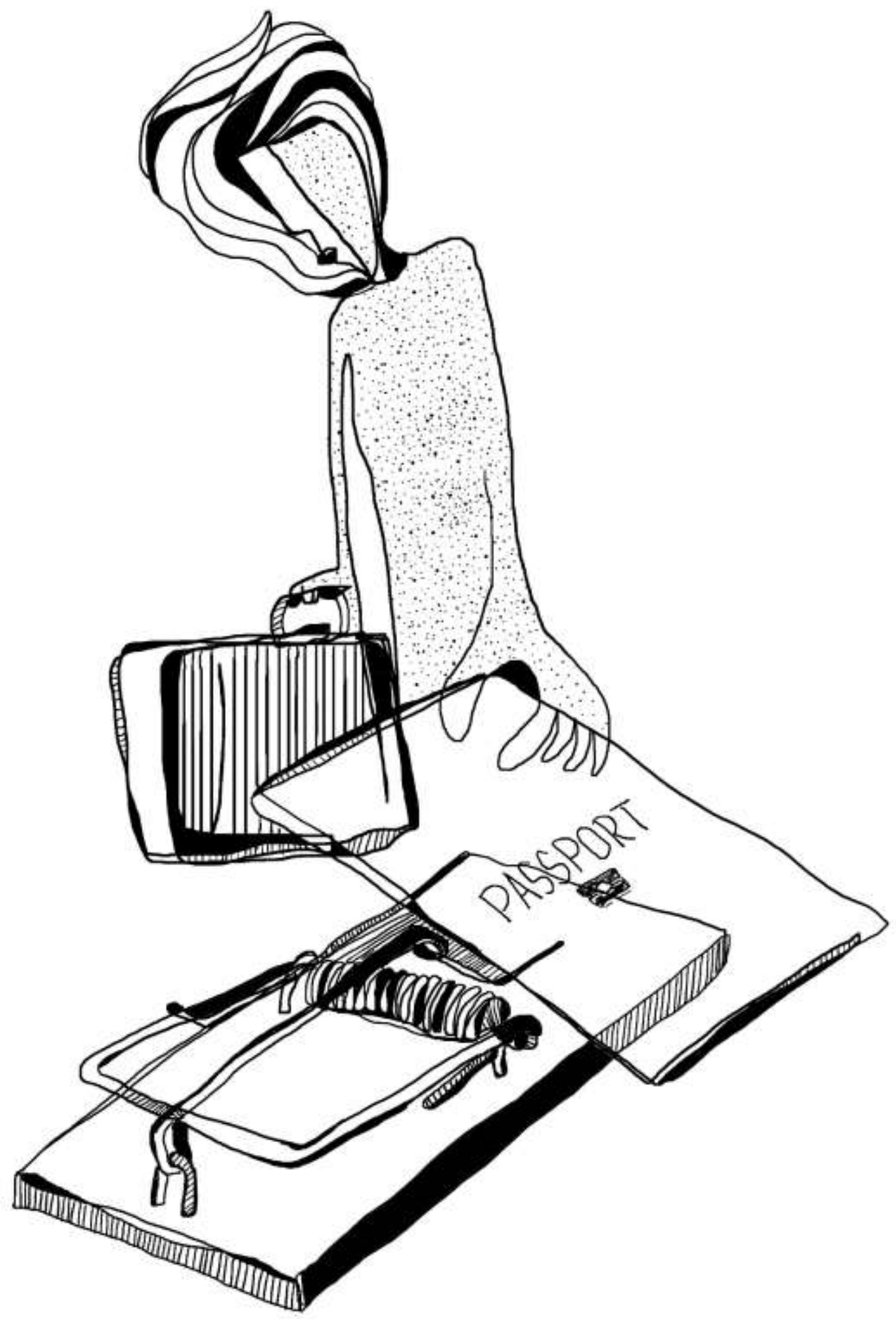

"Take it or leave it." The borders trap. [1/3 The Human Trap] 


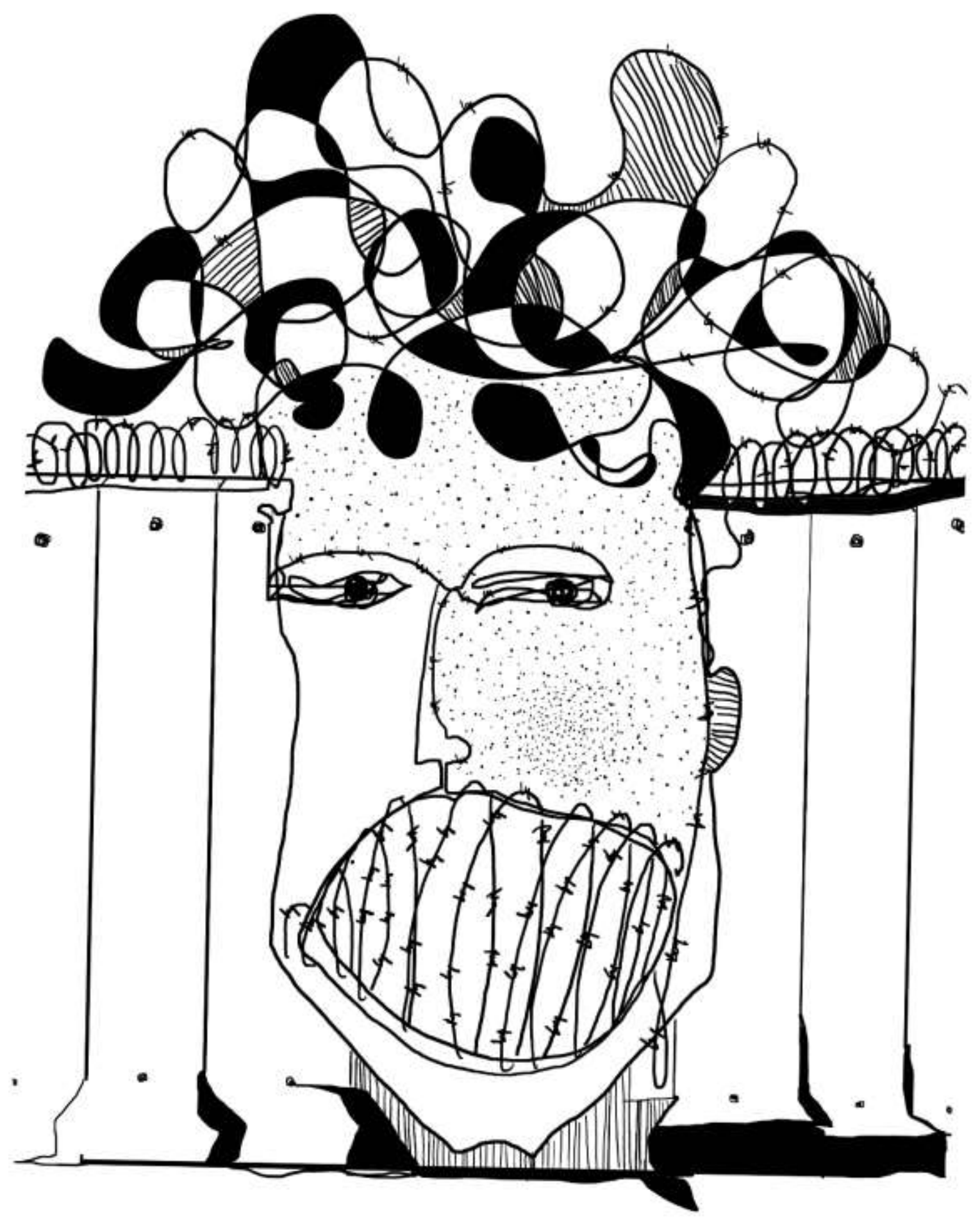

"Anything you say will be held against you." Freedom of speech. [2/3 The Human Trap] 


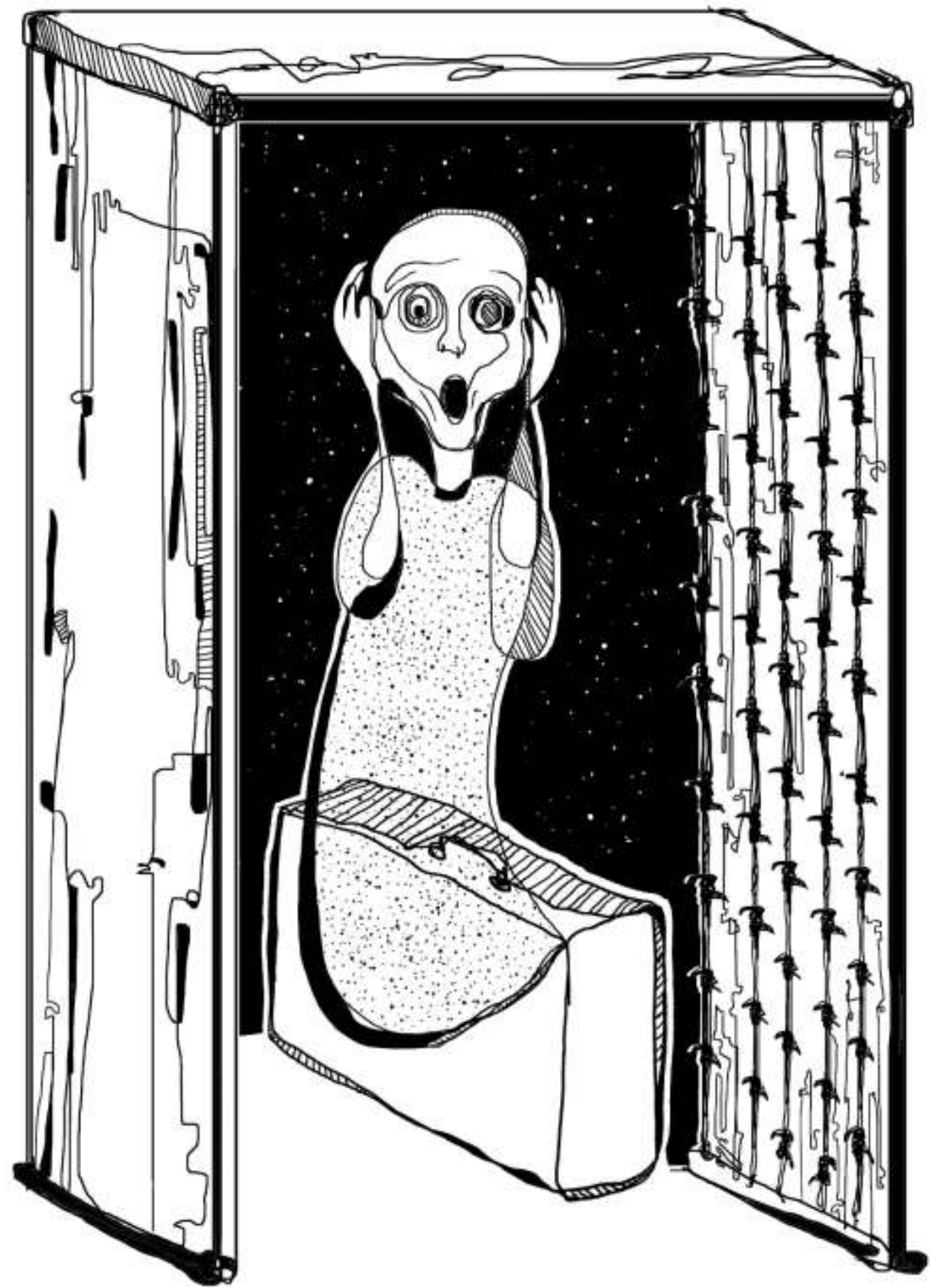

"Aliens are not welcome." The new scream. [3/3 The Human Trap] 